\title{
A Compact Design of Slots Loaded Microstrip Patch Antenna for dual band operation
}

\author{
Niraj Narayan,Avinash Rai \\ Department of Electronics and Communication Uit rgpv Bhopal,India
}

\begin{abstract}
In this paper, a compact design of microstrip patch antenna for defense and satellite communication isdesigned and results are analyzed through HFSS.Three slots are loaded on the top of the patch to enhance the bandwidth of reference rectangular microstrip patch antenna.The simulated antenna return loss is $-18.5 \mathrm{~dB}$ at $6.75 \mathrm{GHz},-18.2 \mathrm{~dB}$ at $11.8 \mathrm{GHz}$ and found bandwidth of $82.2 \%$ and $38.03 \%$ at $6.75 \mathrm{GHz}, 11.8 \mathrm{GHz}$ respectively.
\end{abstract}

Keywords—Microstrip patch antenna, Dual band, Slotted, High Bandwidth, Wireless, HFSS.

\section{INTRODUCTION}

Microstrip patch antennas are transmitting and receiving antennaswith numerous applications in different fields such as satellite communication, radar, remote sensing, GPS receivers and other mass-produced wireless products. Microstrip patch antennas are popular due to their attractive features, such as compactness, low profile planar structure, light weight, and compatibility with integrated circuits [1-4].In spite of, narrow bandwidth is a considerable problem of microstrip patch antennas that restricts its applications. There are various bandwidth enhancement techniques but the simplest one is the loading of different shape and size of slots and notches on the patch or in the ground plane [5]. A number of researchers have reported microstrip patch antennas with enhanced bandwidth such as compact broadband slotted rectangular microstrip antenna with bandwidth of 26.7\% [4],M-slot folded patch antenna reported bandwidth of 21.17\% [6], and W-shaped microstrip patch antenna reported $36.75 \%$ bandwidth [7].

In this paper, slots loaded dual-band microstrip patch antenna has been designed and analyzed to obtaining improved bandwidth for wireless applications. By selecting proper dimensions and positions of the slots, $3 \mathrm{~dB}$ bandwidth improved up to more than $80 \%$ of the resonant frequency. The proposed antenna is optimized using HFSS simulation softwareand results are discussed in terms of antenna parameters.

\section{ANTENNA DESCRIPTION}

Designed antenna structure shown in figure .1 consist radiating patch of copper on porcelain dielectric substrate of relative permittivity 5.7 and having thickness of $1.6 \mathrm{~mm}$. Multiband behavior of patch antenna is obtained by providing three slots of dimensions $\mathrm{L}_{1} \times \mathrm{W}_{1}, \mathrm{~L}_{2} \times \mathrm{W}_{2}$ and $\mathrm{L}_{3} \times \mathrm{W}_{3}$ near the radiating edges of patch [1-4]. Table. I mentioned shows the dimensions of proposed antenna.

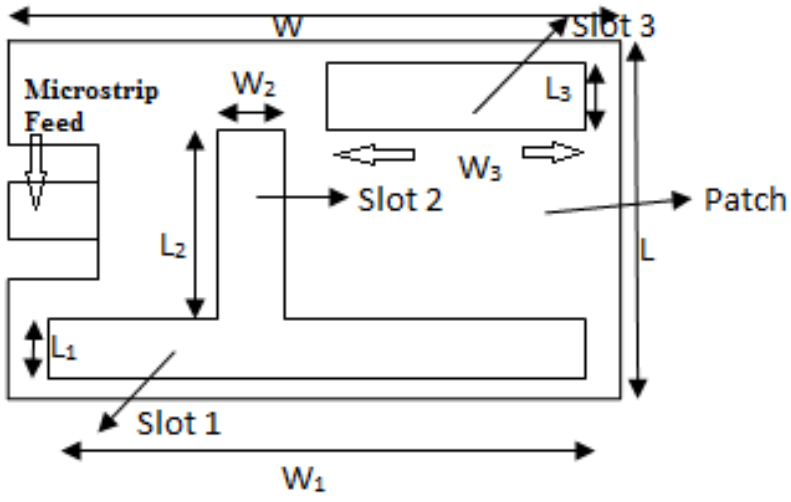

Figure 1. Geometry of proposed antenna

The parameters of the patch are calculated by the following equations [1-3].

Width:

$\mathrm{W}=\frac{\mathrm{u}}{2 \mathrm{f}_{\mathrm{r}}} \sqrt{\frac{2}{\epsilon_{\mathrm{r}}+1}}$

where

$\mathrm{u}=$ free space velocity

$\mathrm{f}_{\mathrm{r}}=$ resonant frequency 
$\varepsilon_{\mathrm{r}=}$ relative permittivity

Effective dielectric constant:

For $\frac{w}{h}>1$

$\varepsilon_{\text {reff }}=\frac{\epsilon_{r}+1}{2}+\frac{\epsilon_{r}-1}{2}+\left[1+12 \frac{h}{w}\right]^{-\frac{1}{2}}$

Length:

$L=\frac{u}{2 f_{r} \sqrt{\varepsilon_{r e f f}}}$

TABLE. I ANTENNA DIMENSIONS

\begin{tabular}{|l|l|}
\hline Parameter & Value \\
\hline Width of patch(W) & $25 \mathrm{~mm}$ \\
Substrate thickness(h) & $38 \mathrm{~mm}$ \\
Dielectric constant of substrate $\left(\varepsilon_{\mathrm{r}}\right)$ & $1.6 \mathrm{~mm}$ \\
Slot $1\left(\mathrm{~L}_{1} \times \mathrm{W}_{1}\right)$ & 5.7 \\
Slot $2\left(\mathrm{~L}_{2} \times \mathrm{W}_{2}\right)$ & $5 \mathrm{~mm} \times 36 \mathrm{~mm}$ \\
Slot $3\left(\mathrm{~L}_{3} \times \mathrm{W}_{3}\right)$ & $5 \mathrm{~mm} \times 16 \mathrm{~mm}$ \\
\hline
\end{tabular}

\section{RESULTS AND DISCUSSIONS}

The proposed patch antenna is simulated using ansoft HFSS v.13 and simulated results of return are shown in figure 2. The return loss of $-18.5 \mathrm{~dB}$ is obtained at $6.75 \mathrm{GHz}$ with $10 \mathrm{~dB}$ bandwidth of $82.2 \%$. The return loss at second resonant frequency $11.8 \mathrm{GHz}$ is $-18.2 \mathrm{~dB}$ with $10 \mathrm{~dB}$ bandwidth of $38.03 \%$.

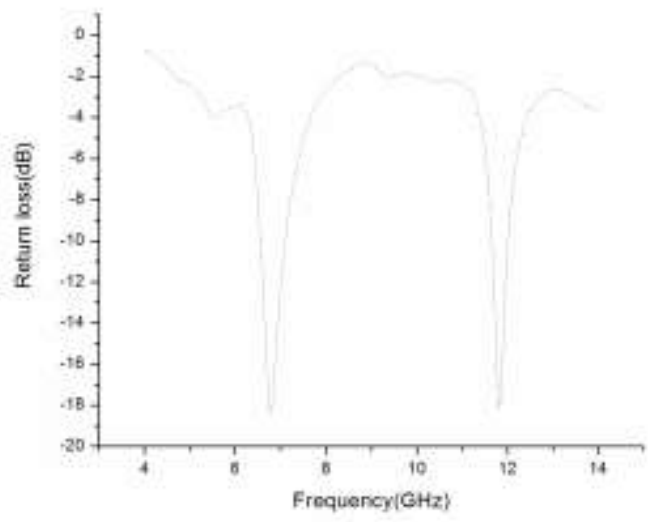

Figure 2. Return loss vs. Frequency of Proposed antenna

Simulated value of voltage standing wave ratio (VSWR) shown in figure 3 are observed as 1.17 and 1.2 which are close to 1 . 


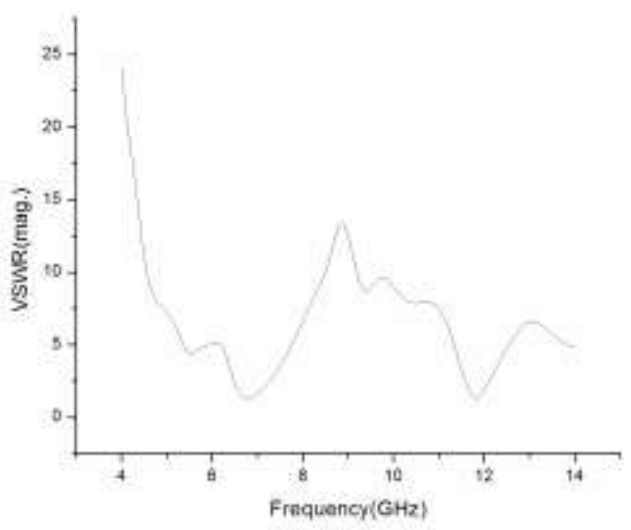

Figure 4. VSWR vs. Frequency of Proposed Antenna

\section{CONCLUSIONS}

A dual band microstrip patch antenna with slots loaded on radiating patch is proposed and simulated for wireless applications at $6.75 \mathrm{GHz}$ and $11.8 \mathrm{GHz}$. With the introduction of the slots the bandwidth has been achieved up to $82.2 \%$ of resonant frequency. This antenna is very simple and convenient for design.

\section{REFERENCES}

[1] Garg.R.,Bhartia.P.,Bahl I.andIttipiboon A. "Microstrip Antenna Design Hnadbook”Artech House Norwood 2001.

[2] Lee, Y.C., Sun, J.S., “A new printed antenna for multiband wireless applications, ” IEEE Antennas Wireless Propaation Letters, 8, 402-404(2009).

[3] P.Subbulakshmi,R.Rajkumar, "Design and characterization of corporate feed Rectangular Microstrip Patch Array Antenna," IEEE International conference on Emerging trends in Computing and Nanotechnology (ICECCN-2013).

[4] A.A Deshmukh and K.P. Ray, "Compact broadband slotted rectangular microstrip antenna," IEEE Antennas and Wireless Propagation Letters, vol. 8, pp. 1410-1413, 2009.

[5] Arnab Das, Bipa Datta, Samiran Chatterjee, Noumita Mukherjee, Santosh Kumar Chowdhury, "Multi-resonant Slotted Microstrip Antenna for C, X and Ku-Band applications, " IOSR Journal of Electrical and Electronics Engineering, ISSN :( 22781678) Volume 2, Issue 6 (Sep.-Oct. 2012), PP 47-52.

[6] F. Jolani, A. M. Dadgarpour, H. R. Hassani, “Compact M-slot folded patch antenna for WLA,” Progress in Electromagnetics Research, vol. 3, pp. 35-42, 2008

[7] A. A. Lotfi Neyestanak, F. Hojjat Kashani, K. Barkeshli, "W-shaped enhanced-bandwidth patch antenna for wireless communication," Wireless Personal Communications, vol. 43, no. 4, pp. 1257-1265, 2007. 